\title{
Production of Lymphotoxin by Isolated Human Tonsillar $B$ Lymphocytes and B Lymphocyte Cell Lines
}

Sun-Sang J. Sung, Lawrence K. L. Jung, Jay A. Walters, Edward W. B. Jeffes III,*‡ Gale A. Granger, ${ }^{\ddagger}$ and Shu Man Fu Immunology Program, Oklahoma Medical Research Foundation, Oklahoma City, Oklahoma 73104; *Department of Dermatology and ${ }^{\ddagger}$ Department of Molecular Biology and Biochemistry, University of California at Irvine, Irvine, California 92717; and

*Dermatology, Veterans Administration Medical Center, Long Beach, California 90822

\begin{abstract}
The expression of lymphotoxin (LT) mRNA and cytokine in human tonsillar B cells and B cell lines was examined by Northern blots and cytotoxicity assays, respectively. In tonsillar B cells, phorbol myristate acetate (PMA) or Staphylococcus aureus Cowan I (SAC) alone induced low levels of LT mRNA accumulation. However, SAC and anti- $\mu$ were strongly synergistic with PMA in this induction. Peak LT mRNA expression in tonsillar B cells stimulated by PMA plus SAC occurred between 48 and $72 \mathrm{~h}$ and was approximately half as much as that in PMA plus anti-CD3-stimulated T cells. $\mathrm{Cy}$ closporine A was not effective in inhibiting LT mRNA accumulation by stimulated tonsillar B cells. A number of $B$ cell lines could also be stimulated by PMA to express LT mRNA. Peak accumulation of LT mRNA in the cell line RPMI 1788 stimulated with PMA peaked about 8 h. A23187 in combination with PMA caused this accumulation to increase slightly and to peak earlier. The cytotoxic effects in the supernatants of stimulated B cells were contributed mostly by LT. The results indicate that tonsillar B cells are important in LT production and that there are important differences in the stimulation requirements for LT production and in LT mRNA expression kinetics between tonsillar B cells and B cell lines.
\end{abstract}

\section{Introduction}

Lymphotoxin (LT) ${ }^{1}$ is a cytokine identified initially as a cytotoxic factor produced by mitogen- or antigen-stimulated $\mathrm{T}$ cells $(1,2)$. Recent studies have shown that LT is highly homologous to tumor necrosis factor (TNF) and shares a number of biologic activities with TNF (see reviews in references 3 and 4). LT and TNF stimulate B and T lymphocyte proliferation

Dr. Jung's present address is Department of Pediatrics, University of Massachusetts Medical School, Worcester, MA 01655; Dr. Fu's present address is Division of Rheumatology, University of Virginia School of Medicine, Charlottesville, VA 22908.

Address reprint requests to Dr. Sung, Immunology Program, Oklahoma Medical Research Foundation, 825 N. E. 13th Street, Oklahoma City, OK 73104.

Received for publication 1 December 1988 and in revised form 20 March 1989.

1. Abbreviations used in this paper: BCGF, B cell growth factor; CsA, cyclosporine A; LT, lymphotoxin, tumor necrosis factor- $\beta$; TNF, tumor necrosis factor, cachectin, tumor necrosis factor- $\alpha$; SAC, Staphylococcus aureus Cowan I.

J. Clin. Invest.

(c) The American Society for Clinical Investigation, Inc.

0021-9738/89/07/0236/08 \$2.00

Volume 84, July 1989, 236-243
(5-7), neutrophil respiratory burst and degranulation $(8,9)$, and osteoclast bone resorption $(8,10)$. They also induce inflammatory reactions in normal skin $(8,11)$, and have antiviral effects (12). In humans, T lymphocytes have been considered the major LT-producing cell type (3). EBV-transformed B cell lines, however, are good sources of LT.

The production of LT by primary B cells has not been extensively examined. Recently, B1-bearing tonsillar B cells have been demonstrated to secrete an LT-like product (13). Tonsillar B lymphocytes can also produce TNF (14). In view of the close homology and tandem arrangement of LT and TNF genes $(2,8)$, it is of interest to examine LT production by $B$ cells and compare the regulation of the syntheses of the two cytokines by B cells. Our data presented in this report demonstrate that $(a)$ tonsillar B cells and B cell lines accumulate LT mRNA and synthesize LT when appropriately stimulated, (b) there are differences in the kinetics of LT and TNF mRNA accumulation in B cells, and $(c)$ there are differences in stimulation requirements for LT production and in the kinetics of LT mRNA expression between tonsillar B cells and B cell lines.

\section{Methods}

Reagents. The preparation of goat anti- $\mu$ and rabbit anti-LT antisera has been described $(14,15)$. The LT antiserum has $1 \times 10^{6}$ neutralizing units/ml. B cell growth factor (BCGF) was obtained from Cellular Products (Cambridge, MA). The sources of other reagents have been described (14). Cyclosporine A (CsA) was from Sandoz Inc. (East Hanover, NJ).

Cells. Tonsillar B cells were purified and maintained in RPMI-1640 with $10 \%$ FCS as described (16). Purified B cell preparations contained $<0.1 \%$ macrophages and $>95 \% \mathrm{Ig}^{+}$and $>98 \% \mathrm{Bl}^{+}$ cells, as determined by fluorescence measurements on a flow cytometer (Cytofluorograf IIs, Ortho Diagnostic Systems, Inc., Westwood, MA). Tonsillar T cells were isolated by E-rosetting twice. These cells were $>95 \% \mathrm{CD}^{+}$and $\mathrm{CD}^{+}$. The sources and surface Ig phenotypes of the B cell lines used were described previously (14).

Northern blot analyses. Methods for Northern blot analyses using RNA prepared by guanidinium thiocyanate ultracentrifugation have been described (16). The human TNF cDNA probe from Drs. B. Beutler (Howard Hughes Medical Institute, Dallas, TX) and D. Caput (Chiron Research Laboratories, Emeryville, CA) and the chicken $\beta$ actin probe from Dr. M. Kirschner (University of California, San Francisco, CA) were used in Northern blot analyses as described (14, 16). LT mRNA was probed by a 0.8 -kb Pst I exon 4 genomic fragment located immediately upstream of the 3.4-kb TNF Pst I fragment (17). LT mRNA detection by the genomic probe was confirmed by the use of two antisense 24-mer oligonucleotide probes (16) and the Northern blot results obtained with all three probes were identical. Hybridization of nick-translated probes with RNA blots (14) was performed overnight at $42^{\circ} \mathrm{C}$ in $50 \%$ formamide, $1 \mathrm{M} \mathrm{NaCl}, 1 \% \mathrm{SDS}, 50 \mathrm{mM}$ sodium phosphate, pH 7.0, $10 \mathrm{mM}$ EDTA, and $100 \mu \mathrm{g} / \mathrm{ml}$ salmon sperm DNA. Blots were washed as described (14) with the high stringency washes performed in $0.1 \times \mathrm{SSC}$ and $1 \% \mathrm{SDS}$ at $65^{\circ} \mathrm{C}$ twice for $30 \mathrm{~min}$ 
each. Hybridized blots were exposed to XK-1 (Eastman Kodak Co., Rochester, NY) or Cronex 4 (Dupont Co., Wilmington, DE) films at $-70^{\circ} \mathrm{C}$ with Dupont lightning plus intensifying screens. Multiple exposures with two- or threefold increases in exposure time were performed consecutively to obtain optimal exposures for quantitation by densitometry. ${ }^{2}$ Band intensities of LT and actin mRNA were quantitated by densitometric scanning of the appropriately exposed X-ray films with a densitometer (model 2202 Ultroscan Laser Densitometer, LKB Instruments, Inc., Gaithersburg, MD). Peak intensities within the range of 0.05-2 absorbance units were approximately linear. Peak areas were measured by a model 9874A Digitizer (Hewlett-Packard Co., Palo Alto, CA) equipped with a model 9815 A data handler (Hewlett-Packard Co.).

Other methods. The L-cell cytotoxicity assay for LT and TNF was carried out as described (16). For neutralization studies, samples were mixed with anti-LT antiserum $\left(1 \times 10^{6}\right.$ neutralization units $\left./ \mathrm{ml}\right)$ at 2 $\times 10^{4} \mathrm{U} / \mathrm{ml}$ or anti-TNF MAb (F12 [16]) at $20 \mu \mathrm{g} / \mathrm{ml}$ (the neutralization activity of $F 12$ is $20 \mathrm{ng} \mathrm{TNF} / \mu \mathrm{g} \mathrm{Ab}$ ) overnight before the serial dilutions and addition to the $\mathrm{L}$ cells.

\section{Results}

LT mRNA expression in tonsillar B cells stimulated by PMA, $S A C$, anti- $\mu$, and $B C G F$. Tonsillar B cells were stimulated by the combination of various $B$ cell mitogens and examined for LT mRNA accumulation at $24 \mathrm{~h}$. SAC and PMA stimulated low levels of LT mRNA expression (Fig. $1 A$, lane 2; $B$, lanes 1 and 2; $C$, lane 3), while anti- $\mu$ (Fig. $1 C$, lane 2) and BCGF (not shown) did not cause any detectable LT mRNA expression. However, the actions of several of them were synergistic. Like the T cell system (16), in which two signals were required for the induction of lymphokine production, the stimulation of high levels of LT mRNA accumulation required the combination of SAC or anti- $\mu$ with PMA (Fig. $1 A$, lane 3; $B$, lanes 3 and 4; $C$, lane 4). BCGF enhanced SAC and PMA stimulation by about twofold (Fig. $1 A$, lane 5 ; $C$, lane 5), but only marginally increased LT mRNA accumulation stimulated by the combinations of SAC plus PMA (Fig. $1 A$, lane 6 ), or anti- $\mu$ plus PMA (Fig. $1 C$, lane 7). Anti- $\mu$ antagonized the effect of SAC on LT mRNA accumulation in tonsillar $B$ cells, and abolished LT mRNA production in B cells stimulated with SAC or SAC plus BCGF (Fig. $1 A$, lanes 4 and 7). Experiments in which the stimulatory potency of SAC plus PMA and anti- $\mu$ plus PMA were compared (Fig. $1 B$, lanes 3 and 4 ) showed that anti- $\mu$ plus PMA was slightly higher at $24 \mathrm{~h}$.

LT mRNA expression in B cell lines. LT mRNA accumulation was examined in a number of $B$ cell lines expressing different Ig phenotypes (Fig. $2 \mathrm{~A}$ ). Most of them expressed undetectable to low levels of LT mRNA constitutively. With PMA stimulation, most cell lines expressed LT mRNA. SeD, 8866p, 32al, and RPMI 1788 expressed high levels of LT mRNA with RPMI 1788 expressing four- to fivefold more than the other three cell lines. Of interest is the finding that the pre-B cell lines Nalm- 6 and Nalm-12 did not express LT message even when stimulated by PMA (Fig. $2 A$, lanes 16 and 18 ). A number of other Ig-producing EBV-transformed cell lines

2. For long exposures, the radioactive decay of ${ }^{32} \mathrm{P}$ was adjusted by using an exposure time obtained by integration of the formula $N=N_{0}$ $\exp (-\lambda t)$, where $N$ is the amount of radioactivity at any given time $t, N_{0}$ is the initial amount of radioactivity, and $\lambda=0.0485$ for ${ }^{32} \mathrm{P}$. For twofold exposures, and time of start of exposure $t_{0}=0, t_{2}=-(1 / \lambda) \ln [3$ $\left.\exp \left(-\lambda t_{1}\right)-2\right]$, where $t_{1}$ is the time for developing the $1 \times$ exposure and $t_{2}$ is the time for developing the $2 \times$ exposure.

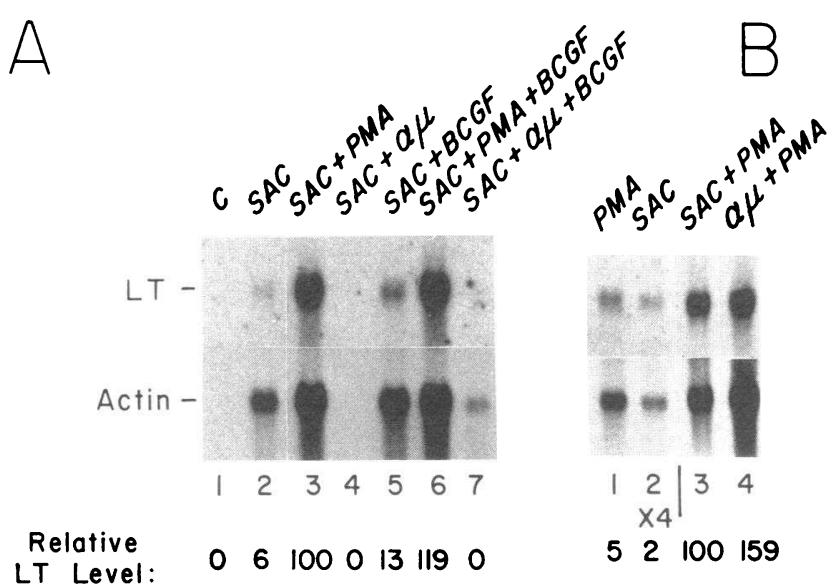

LT Level:
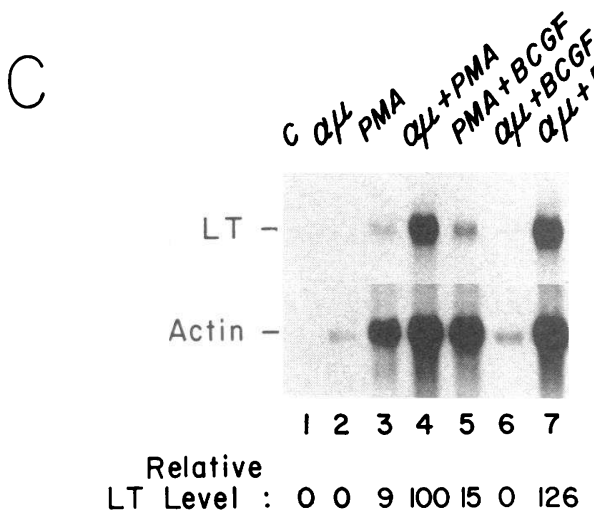

Figure 1. LT mRNA expression in tonsillar B cells stimulated by combinations of PMA with $(A)$ SAC, $(B)$ both SAC and anti- $\mu$, or (C) anti- $\mu$. Purified tonsillar B cells were resuspended at $1 \times 10^{6} / \mathrm{ml}$ and stimulated for $24 \mathrm{~h}$ with PMA $(10 \mathrm{ng} / \mathrm{ml})$, goat anti- $\mu$ IgG $(25$ $\mu \mathrm{g} / \mathrm{ml}), \operatorname{SAC}(0.01 \%)$, BCGF $(5 \%)$ or their combinations. The cells were collected and lysed in guanidinium isothiocyanate. The total RNA was isolated by ultracentrifugation and analyzed as described in Methods. The same blots were hybridized sequentially with LT and $\beta$-actin probes. The results are representative of five similar experiments. $(A)$ Stimulation of LT mRNA accumulation by PMA and SAC. Tonsillar B cells $\left(28 \times 10^{6}\right.$ cells per sample) were treated with control medium (lane 1), SAC (lane 2), SAC plus PMA (lane 3), SAC plus anti- $\mu$ (lane 4), SAC plus BCGF (lane 5), SAC plus PMA plus BCGF (lane 6), and SAC plus anti- $\mu$ plus BCGF (lane 7). The intensity of LT mRNA band in each lane was determined by densitometry and expressed as percentage of the LT mRNA intensity of cells treated with SAC plus PMA (lane 3). (B) The LT mRNA levels of tonsillar B cells stimulated with SAC plus PMA and anti- $\mu$ plus PMA were shown in the same experiment. Cells $\left(21 \times 10^{6}\right.$ per sample) were treated with PMA (lane 1), SAC (lane 2), SAC plus PMA (lane 3), and anti- $\mu$ plus PMA (lane 4). LT mRNA levels were expressed as percentage of that of cells treated with SAC plus PMA. The LT mRNA signals in lanes 1 and 2 were from films that were exposed four times longer than that in lanes 3 and 4. (C) Stimulation of LT mRNA accumulation by PMA and anti- $\mu$. The tonsillar B cells $\left(17 \times 10^{6}\right.$ cells per sample) were treated with control medium (lane 1 ), anti- $\mu$ (lane 2), PMA (lane 3), anti- $\mu$ plus PMA (lane 4), PMA plus BCGF (lane 5), anti- $\mu$ plus BCGF (lane 6 ), and anti- $\mu$ plus PMA plus BCGF (lane 7). The intensities of LT mRNA were expressed as percent of that of cells treated with anti- $\mu$ plus PMA (lane 4).

derived from bone marrow cells were further studied (Fig. $2 B$ ). These cell lines produced LT mRNA constitutively. PMA stimulation increased their LT mRNA accumulation two- to 
A
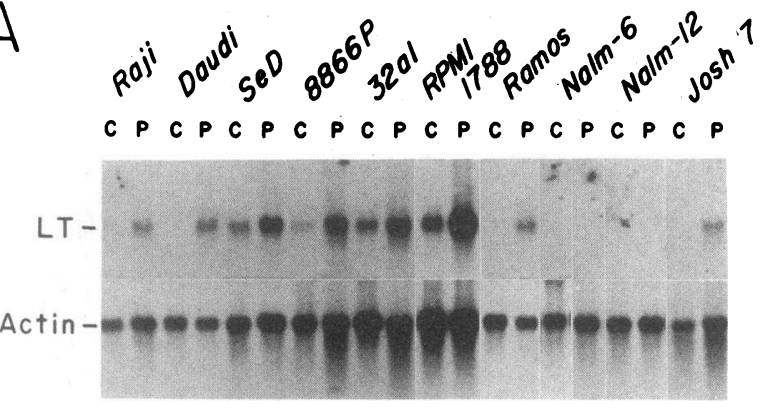

1234567891011121314151617181920

Relative $T_{\text {Level: }}^{3} 0^{5} 5^{18} 2^{22} 7^{20} 16^{100} 0^{4} 0^{0} 0^{0} 0^{3}$

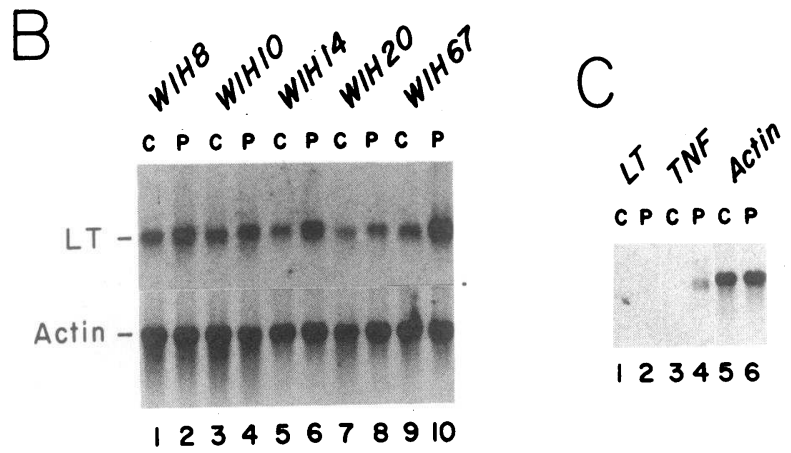

$\stackrel{\text { Relative }}{11^{19}} 12^{14} 7^{21} 6^{7} 8^{31}$

Figure 2. Expression of LT mRNA by human B cell lines. Total RNA isolated from cell lines as in Methods were purified by oligo(dT)-cellulose. The poly $\mathrm{A}^{+}$RNA samples were analyzed as in Fig. 1. Samples in all three panels were analyzed in the same experiment and all the lanes hybridized with the same probe were exposed for the same period of time. The relative LT mRNA levels shown at the bottom of each panel were expressed as the percentage of the intensity of the most intense band ( $A$, lane 12 , PMA-stimulated RPMI 1788). ( $A$ ) PolyA ${ }^{+}$RNA (5 $\mu$ g per lane) from Raji (lanes $l$ and 2 ), Daudi (lanes 3 and 4), SeD (lanes 5 and 6), 8866p (lanes 7 and 8), 32al (lanes 9 and 10), RPMI-1788 (lanes 11 and 12), Ramos (lanes 13 and 14), Nalm-6 (lanes 15 and 16), Nalm- 12 (lanes 17 and 18), and Josh-7 (lanes 19 and 20) were analyzed as in Fig. 1. Odd numbered lanes ( $C$ lanes) contained mRNA from unstimulated cells and even numbered lanes $(P$ lanes $)$ had mRNA from cell lines $\left(1 \times 10^{6} \%\right.$ $\mathrm{ml}$ ) stimulated for $4 \mathrm{~h}$ with $10 \mathrm{ng} / \mathrm{ml}$ PMA. $(B)$ Northern blots of $\mathrm{A}^{+}$-RNA from bone marrow-derived EBV-transformed cell lines WIH8 (lanes 1 and 2), WIH10 (lanes 3 and 4), WIH14 (lanes 5 and 6), WIH20 (lanes 7 and 8 ) and WIH67 (lanes 9 and 10). Hybridizations with nick-translated probes were as in Fig. 1. Odd numbered lanes ( $C$ lanes) contained mRNA from unstimulated cells and even numbered lanes $(P$ lanes) contained mRNA from PMA-stimulated cells. $(C)$ Comparison of LT and TNF expression in Nalm-12. The blot was performed as in Fig. 1. $C$ lanes were control lanes and $P$ lanes were RNA from PMA-stimulated cells. $5 \mu \mathrm{g}$ of $\mathrm{A}^{+}$-RNA were applied in each lane. The same blot was probed sequentially with LT, TNF, and $\beta$-actin probes.

fourfold. The relative levels of LT mRNA expression in all these B cell lines were similar to that of TNF mRNA expression (14), with the exception of the pre-B cell line Nalm-12, which could be stimulated by PMA to synthesize TNF but not LT mRNA (Fig. $2 C$ ).
Time course of LT MRNA accumulation in tonsillar B cells. The time course of LT and TNF mRNA accumulation in tonsillar B cells was compared (Figs. 3 and 4). In terms of mRNA detected per culture, the accumulation of LT mRNA in B cells stimulated with SAC plus PMA was maximal between 48 and $72 \mathrm{~h}$ (Fig. $3 A, 4 A$ ) and gradually decreased thereafter. The peak accumulation of TNF mRNA in these same tonsillar B cells was earlier and occurred in about $48 \mathrm{~h}$. TNF mRNA level decreased rapidly after $48 \mathrm{~h}$. The amount of $\beta$-actin mRNA which reflected the total intracellular mRNA level also increased with time and reached peak values between 40 and $48 \mathrm{~h}$. If the actin mRNA level in the B cells was taken into account, and the specific increase in LT mRNA expression was determined by taking the ratio of the intensities of LT and actin mRNA bands, an early peak at $8 \mathrm{~h}$ was observed for both LT and TNF mRNA accumulation (Fig. $4 B$ ). A second peak of specific mRNA accumulation was found at $48 \mathrm{~h}$ and $32 \mathrm{~h}$ for LT and TNF mRNA, respectively.

The stimulation of B cells by PMA plus SAC and PMA plus anti- $\mu$ to express LT and TNF mRNA was compared in time course studies (Fig. $3 B$, quantitation data not shown). Both combinations of stimuli induced peak LT mRNA accumulation on the second day. PMA plus SAC caused a two- to threefold higher peak LT and TNF mRNA accumulation than PMA plus anti- $\mu$. The time course of TNF mRNA accumulation in PMA plus SAC-stimulated B cells was similar to that of LT mRNA accumulation, reaching peak level on the second day. However, in PMA plus anti- $\mu$-treated B cells, the TNF mRNA level reached plateau level on the first day. The $\beta$-actin mRNA levels in PMA plus SAC-stimulated B cells started to increase at a later time point than B cells treated with PMA plus anti- $\mu$, and did not reach as high a level on the third day.

Time course of LT $m R N A$ accumulation in cell lines. The cell line RPMI 1788 which accumulated the highest LT

A
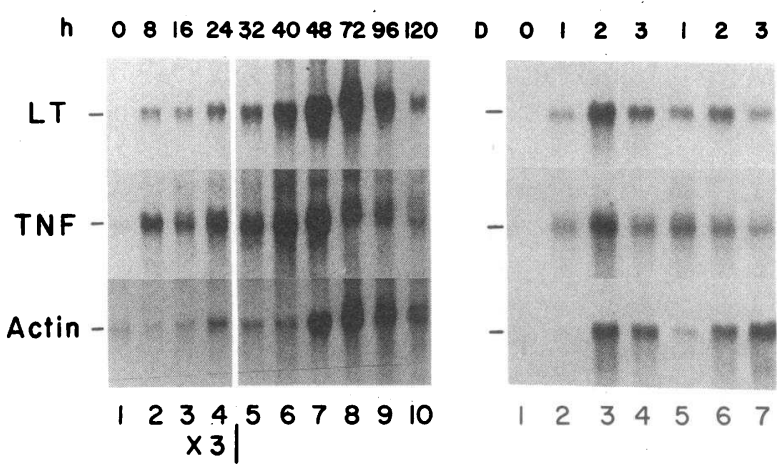

Figure 3. Time course of LT and TNF mRNA expression in tonsillar B cells stimulated with $(A)$ PMA plus SAC or $(B)$ PMA plus anti- $\mu$. (A) Tonsillar B cells at $1 \times 10^{6}$ cells $/ \mathrm{ml}(17 \mathrm{ml}$ per sample $)$ were treated with PMA $(10 \mathrm{ng} / \mathrm{ml})$ plus SAC $(0.01 \%)$ for the time points indicated. Cells were lysed and their RNA was analyzed as in Fig. 1. The same blot was probed successively with LT, TNF, and $\beta$-actin probes. In lanes 5-10, one-third of the total RNA samples was used to avoid overloading. The results are representative of four similar experiments. $(B)$ Tonsillar B cells were incubated with PMA plus SAC (lanes $2-4)$ or PMA $(10 \mathrm{ng} / \mathrm{ml})$ plus anti- $\mu(25 \mu \mathrm{g} / \mathrm{ml})$ (lanes $5-7)$ for the indicated number of days and their total RNA analyzed as in $A$. One of two similar experiments is shown. 

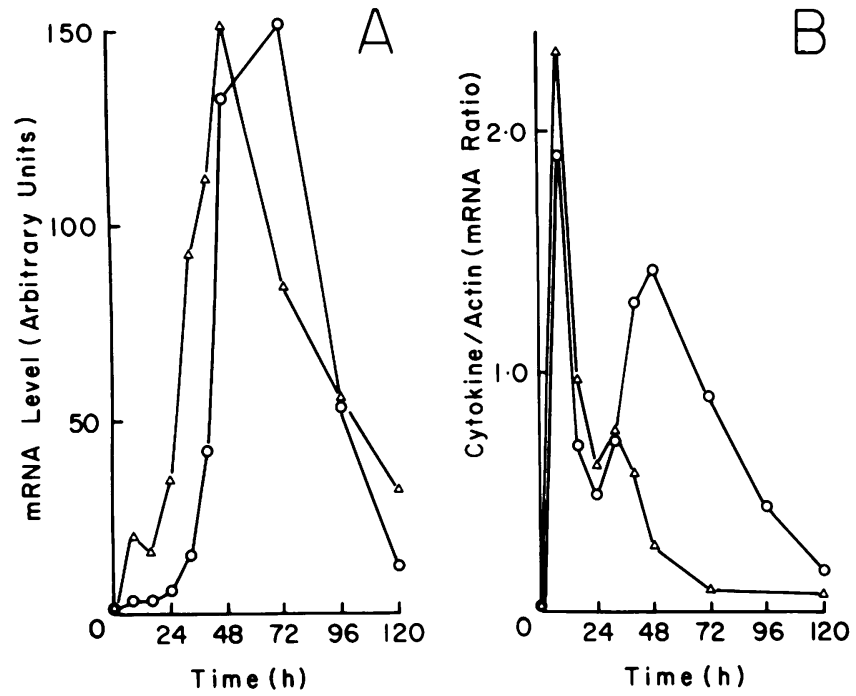

Figure 4. Time course of LT and TNF mRNA accumulation in PMA plus SAC-stimulated tonsillar B cells. The band intensities of LT and TNF mRNA in Fig. $3 A$ were determined by densitometry and plotted in arbitrary units in $A$. The specific LT or TNF mRNA expression is shown in $B$. The cytokine/actin ratio is obtained by dividing the intensities of LT or TNF mRNA bands in arbitrary units by the intensities of the actin mRNA band in arbitrary units at the same time points in $A$. (O) LT mRNA; ( $\triangle$ ) TNF mRNA.

mRNA level upon PMA stimulation (Fig. $2 A$ ) was chosen for time course studies. LT mRNA accumulation in this cell line stimulated with the protein kinase $C$ activator PMA reached peak level at 6-8 h (Fig. 5), and decreased slightly between 8 and $48 \mathrm{~h}$ after stimulation. When a second signal in the form of cytosolic free $\left[\mathrm{Ca}^{2+}\right]$ elevation was delivered by the ionophore A23187, LT mRNA level equal to that of peak accumulation in PMA-stimulated cells was reached between 2 and $4 \mathrm{~h}$. There was a slow twofold increase over the next 20 -h period and the peak LT mRNA level was maintained up to 48 $\mathrm{h}$ after stimulation. There were notable differences in the time course of TNF and LT mRNA accumulation in these cells treated with the same stimuli (Fig. 5). PMA-stimulated TNF mRNA accumulation reached peak level earlier (by $1 \mathrm{~h}$ ), and decreased much more rapidly than LT mRNA accumulation. A23187, when added to PMA stimulated cells, caused a twoto threefold increase in TNF mRNA. It seemed that TNF mRNA was either more unstable than LT mRNA, or its synthesis was terminated earlier.

Comparison of LT and TNF mRNA expression in tonsillar $B$ and $T$ cells. The expression of LT and TNF mRNA in tonsillar B cells stimulated with PMA plus SAC and PMA plus anti- $\mu$ were compared with that in tonsillar $T$ cells stimulated with PMA plus anti-CD3 and PHA. The Northern blots of mRNA from these cells stimulated for 32 and $48 \mathrm{~h}$, the approximate time of the second peak of LT and TNF mRNA accumulation, were shown in Fig. $6 \mathrm{~A}$. As discussed in the previous paragraph (Fig. $3 \mathrm{~B}$ ), tonsillar B cells stimulated with PMA plus SAC accumulated twice as much LT mRNA as those stimulated with PMA plus anti- $\mu$ at 48 h (Fig. $6 \mathrm{~A}$, compare lanes 1 and 2 with lanes 3 and 4 ). For the T cells, PMA plus anti-CD3 was a better set of stimuli than PHA in inducing LT mRNA accumulation, in part because these cells were extensively purified of macrophages. On a per cell basis,
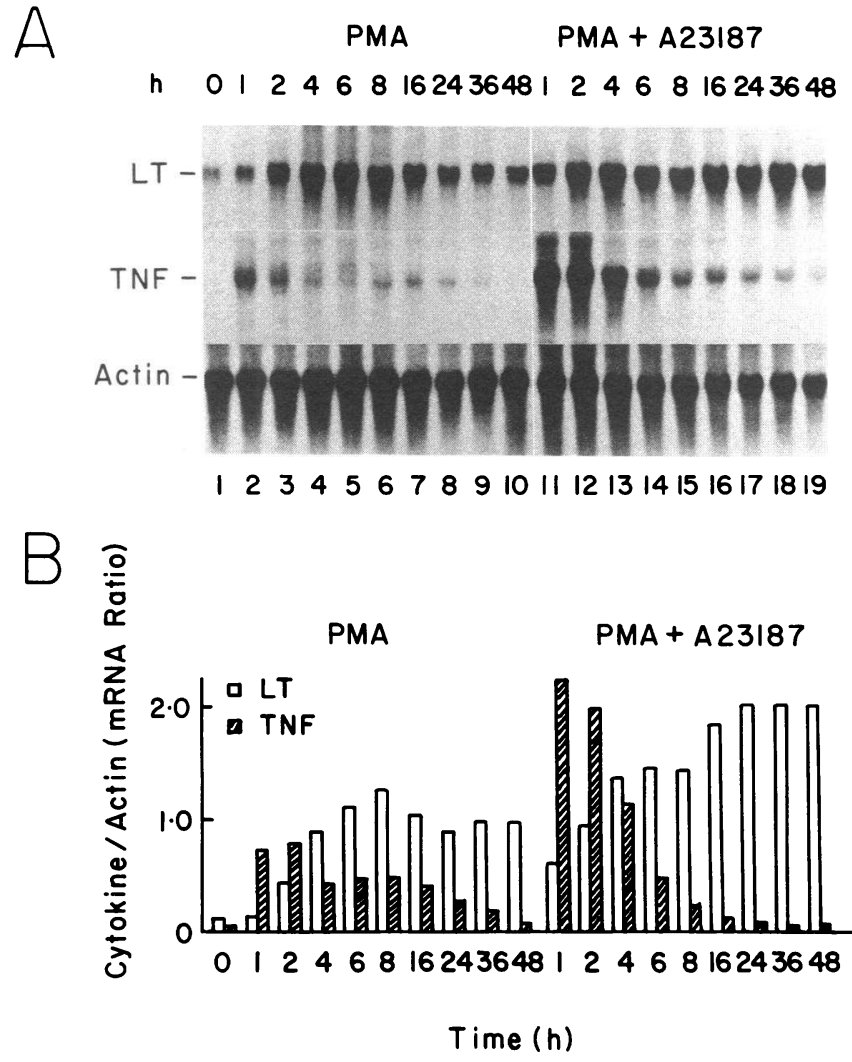

Figure 5. Time course of LT mRNA expression in the B cell lines RPMI 1788. RPMI 1788 cells were suspended at $0.25 \times 10^{6} / \mathrm{ml}$ in medium containing $10 \mathrm{ng} / \mathrm{ml}$ PMA (lanes $2-10$ ) or $10 \mathrm{ng} / \mathrm{ml}$ PMA plus $0.1 \mu \mathrm{M}$ A23187 (lanes 11-19) for the time period indicated. RNA was isolated from the cells as in Fig. 1 and quantitated by absorbance measurement at $260 \mathrm{~nm}$. For Northern analysis, $20 \mu \mathrm{g}$ of total RNA was loaded per lane. The blot was sequentially hybridized with LT, TNF, and $\beta$-actin probes. The results are representative of two similar experiments. In $A$, the results of Northern blot analysis are shown. In $B$, the specific expression of the LT (ם) and TNF (回) mRNA obtained by dividing the intensities of the cytokine mRNA bands by the intensities of the actin mRNA bands at the same time point is shown.

the LT mRNA expression of T cells stimulated with PMA plus anti-CD3 was two- to threefold higher than that of $B$ cells stimulated with PMA plus SAC (Fig. $6 A$, compare lanes 1 and 2 with lanes 5 and 6 ). The relative amounts of TNF mRNA expressed in B cells relative to that in T cells, however, were different. B cells could express one-half (14) to slightly larger amounts (Fig. $6 \mathrm{~A}$ ) of TNF mRNA as T cells, depending upon the individual tonsil examined.

To show that the LT and TNF mRNA detected in these B cell preparations were not due to minor $\mathrm{T}$ cell contaminations, tonsillar $\mathrm{T}$ cells were stimulated with the B cell mitogen combination PMA and SAC. These T cells did not respond well to these stimuli, and expressed little LT and TNF mRNA (Fig. 6 $B$ ). These results support the notion that the tonsillar B cells were the source of the cytokine mRNA detected in the B cell preparations.

Inhibition of LT mRNA by CsA. CsA inhibits the T cell production of IL-2 induced by anti-CD3 (see review in reference 18). To examine if CsA also inhibited the production of LT by B cells, combinations of stimulants that induced LT 


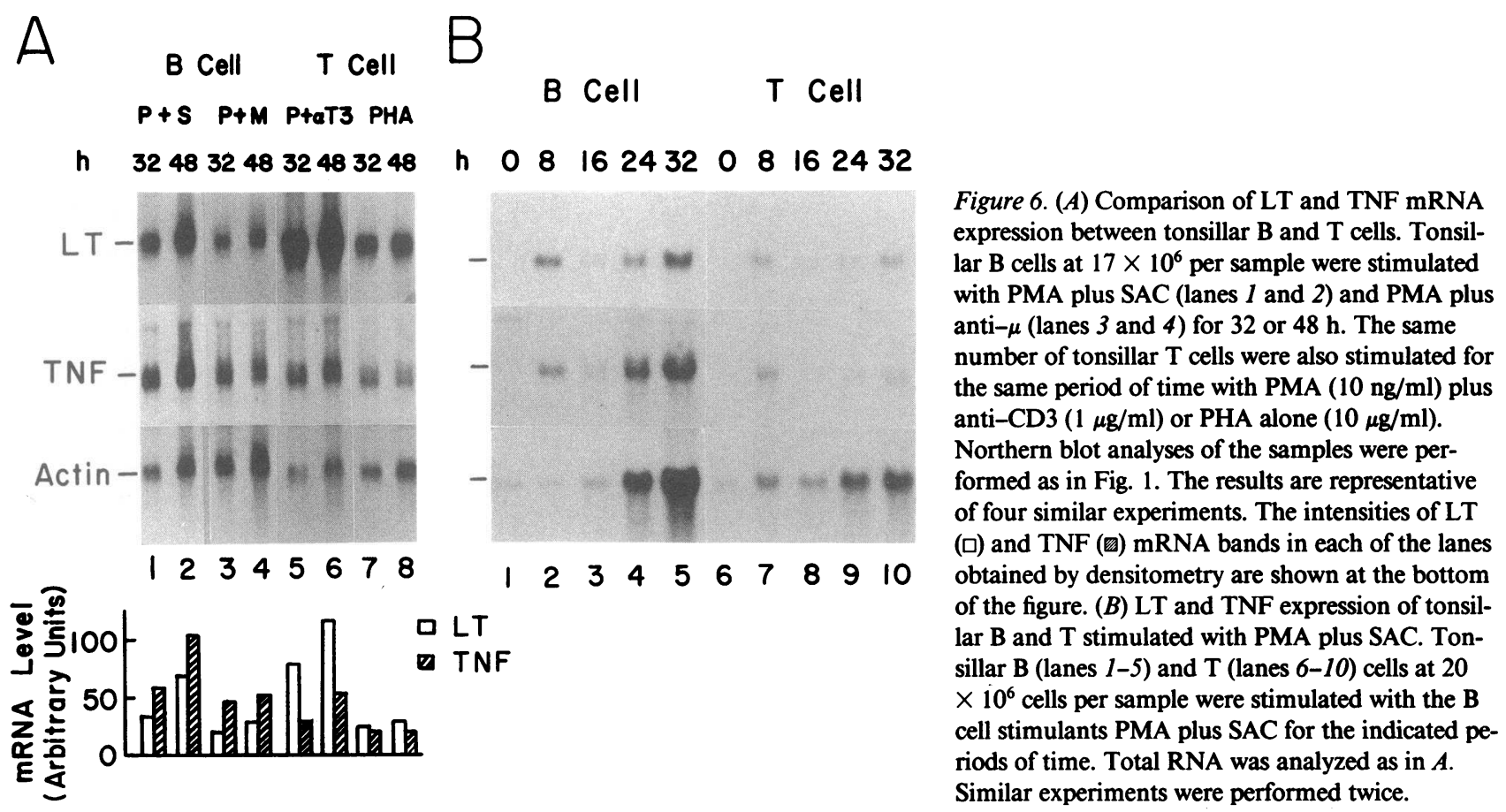

mRNA expression in B cells were used. In several experiments on CsA dose-dependence studies, it was found that LT mRNA synthesis in PMA plus anti-CD3-stimulated $T$ cells was very sensitive to CsA inhibition (Fig. $7 \mathrm{~B}$, lanes 6 and 7). At 100 $\mathrm{ng} / \mathrm{ml} \mathrm{CsA}$, a $96 \%$ decrease in LT mRNA accumulation was observed. On the other hand, LT mRNA level in B cells stimulated with SAC, PMA, SAC plus BCGF and SAC plus PMA were unaffected by CsA at concentrations of 100 and 500 $\mathrm{ng} / \mathrm{ml}$ (Fig. $7 A$ ). At a higher dose of $5 \mu \mathrm{g} / \mathrm{ml}$, LT $\mathrm{mRNA}$ levels in these B cells were inhibited $50-70 \%$ (not shown). Anti- $\mu$ plus PMA stimulation, however, was more sensitive to CsA inhibition, and CsA at $500 \mathrm{ng} / \mathrm{ml}$ inhibited LT mRNA accumulation in these B cells by $60 \%$ (Fig. $7 A$, lane 13 ).

Production of LT by tonsillar B cells and B cell lines. The production of LT by tonsillar B cells and B cell lines was determined by L-cell cytotoxicity assays (15). Tonsillar B cells stimulated with PMA plus anti- $\mu$ synthesized 30-60 U of LT per $10^{6}$ cells over a 3 -d period (Table I). Over the same period of time, cells stimulated with PMA plus SAC synthesized about three times as much LT. By comparison, T cells stimulated with PMA plus anti-CD3 synthesized two to three times more LT than B cells stimulated maximally with PMA plus anti- $\mu$ plus SAC. Control experiments showed that the antiLT antiserum used did not affect the cytotoxicity of rTNF. Furthermore, rabbit anti-TNF antiserum and anti-TNF mAb F12 had little blocking activity on the cytotoxic activities in these supernatants (data not shown), showing that the majority of the cytotoxic activities were due to LT.

The production of LT by EBV-transformed B cell lines was also examined (Table II). LT production by cell lines stimulated with PMA with or without the addition of A23187 was similar. These cell lines expressed in the range of 400-900 $\mathrm{U}$ of LT activity per $10^{6}$ cells over a $24-\mathrm{h}$ period. RPMI 1788 produced the most LT, as has been reported (3). The other two EBV-transformed lines produced about half as much LT as RPMI 1788.

\section{Discussion}

LT and TNF genes are highly homologous, similar in gene segment organization and separated by only $1.2 \mathrm{~kb}$ on human chromosome 6 (17). For these reasons, they are postulated to belong to the same gene family (3). We recently demonstrated that B cells synthesized TNF (14) and Bersani et al. (13) reported the presence of LT-like products in stimulated tonsillar B cell supernatants. These data led us to examine the stimulation of LT mRNA expression and cytokine synthesis in B cells. We found that LT mRNA was expressed in tonsillar B cells stimulated by a variety of B cell mitogens. The detection of LT mRNA by the LT genomic probe was corroborated by the use of two 24-mer LT antisense oligonucleotide probes in Northern blot analyses under high-stringency conditions. The low responses of tonsillar $\mathrm{T}$ cells to the $\mathrm{B}$ cell mitogen combination PMA plus anti- $\mu$ confirmed that this LT mRNA detected in stimulated B cells was not due to contaminating $T$ cells. The use of the LT-specific antisera confirmed the presence of LT cytotoxic activities in the supernatants of stimulated B cells. Thus, it now appears that B cells are an important cell type in producing LT, in addition to the production of TNF (14), IL-1 (19), IL-6 (20), and IFN- $\alpha$ (21).

A number of differences were observed when examining LT and TNF mRNA expression characteristics in tonsillar B cells and B cell lines stimulated by a variety of B cell mitogens. First, as in T cells (14), peak accumulation of TNF mRNA occurred earlier than that of LT mRNA in both tonsillar B cells and B cell lines. Secondly, it appeared that tonsillar B cells played a slightly more significant role in producing TNF than LT. On a per cell basis, tonsillar T cells accumulated two to four times more LT mRNA but less than twofold higher level of TNF mRNA than tonsillar B cells (14, Fig. 6). Thirdly, LT and TNF do not necessarily coexpress in the same cell line. In Nalm 12, TNF mRNA expression was induced by PMA while LT mRNA expression was not. The converse situation was 


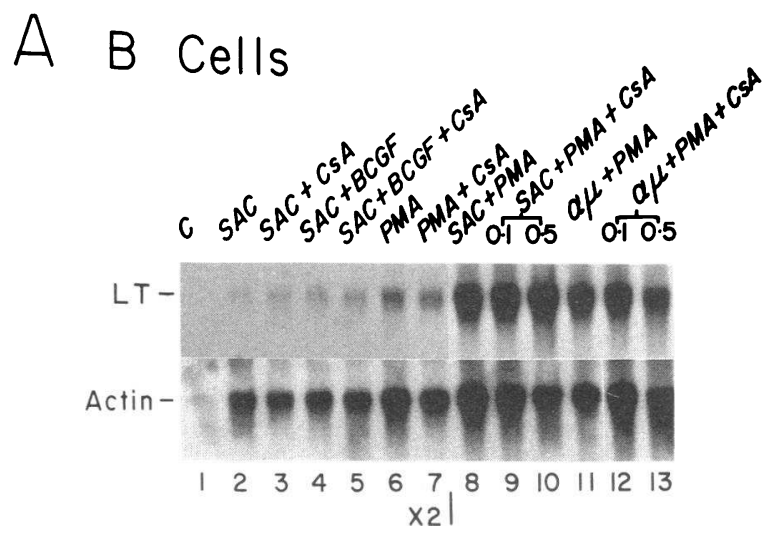

$\begin{array}{llllllllll}\text { Relative } & 0 & 0 & 100 & 118 & & & 98 & 33\end{array}$

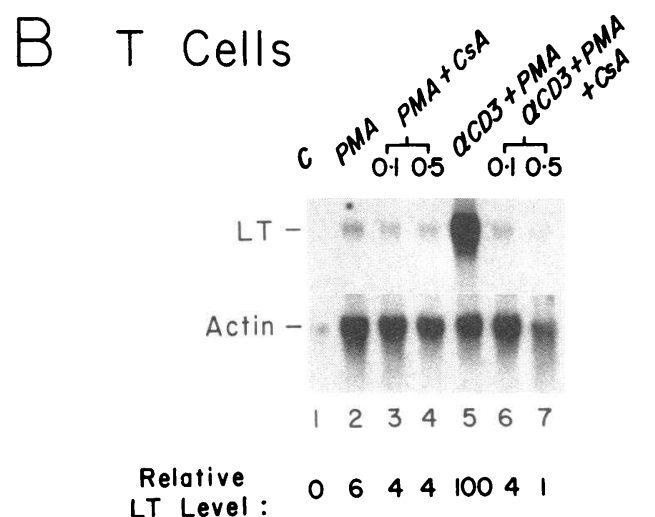

Figure 7. Inhibition of the stimulation of LT mRNA expression by CsA in tonsillar B and $T$ cells. The concentrations of reagents used were described in Fig. 1. Anti-CD3 MAb (A32) was used at $1 \mu \mathrm{g} / \mathrm{ml}$. The samples in both $A$ and $B$ were performed in the same experiment. The results represent one of two identical experiments. Three additional experiments in which $5 \mu \mathrm{g} / \mathrm{ml}$ CsA were used have also been performed. All lanes detected with the same probe were exposed for the same period of time, except the LT lanes $1-7$ in $A$, which were exposed twice as long as the other lanes. The relative LT mRNA levels of lanes in $A$ were expressed as the percentage of the band intensity of LT mRNA in SAC plus PMA-treated cells (lane 8). The relative LT mRNA levels in $B$ were expressed as the percentage of the band intensity of LT mRNA in anti-CD3 plus PMA-treated cells (lane 5). $(A)$ Tonsillar B cells at $17 \times 10^{6}$ cells per sample were treated with the following reagents and their RNA analyzed as in Fig. 1: lane 1, control; lane 2, SAC; lane 3, SAC plus $0.5 \mu \mathrm{g} / \mathrm{ml} \mathrm{CsA;} \mathrm{lane}$ 4, SAC plus BCGF; lane 5, SAC plus BCGF plus $0.5 \mu \mathrm{g} \mathrm{CsA;} \mathrm{lane} 6$, PMA; lane 7, PMA plus $0.5 \mu \mathrm{g} / \mathrm{ml}$ CsA; lane 8 , SAC plus PMA; lane 9, SAC plus PMA plus $0.1 \mu \mathrm{g} / \mathrm{ml}$ CsA; lane 10 , SAC plus PMA plus $0.5 \mu \mathrm{g} / \mathrm{ml} \mathrm{CsA}$; lane 11 , anti- $\mu$ plus PMA; lane 12 , anti- $\mu$ plus PMA plus $0.1 \mu \mathrm{g} / \mathrm{ml} \mathrm{CsA}$; lane 13 , anti- $\mu$ plus PMA plus $0.5 \mu \mathrm{g} / \mathrm{ml} \mathrm{CsA}$. $(B)$ Tonsillar T cells at $17 \times 10^{6}$ cells per sample were treated with the following reagents and their RNA analyzed by Northern blot as in Fig. 1: lane 1, control; lane 2, PMA; lane 3, PMA plus $0.1 \mu \mathrm{g} / \mathrm{ml}$ CsA; lane 4, PMA plus $0.5 \mu \mathrm{g} / \mathrm{ml} \mathrm{CsA}$; lane 5 , anti-CD3 plus PMA; lane 6 , anti-CD3 plus PMA plus $0.1 \mu \mathrm{g} / \mathrm{ml} \mathrm{CsA}$; lane 7 , anti-CD3 plus PMA plus $0.5 \mu \mathrm{g} / \mathrm{ml} \mathrm{CsA}$.

observed in the T cell lines Molt-4 and Jurkat (16). Lastly, in the cell line RPMI 1788 stimulated with PMA plus A23187, LT mRNA level remained elevated for more than $2 \mathrm{~d}$ whereas TNF mRNA decayed rapidly (Fig. 5).
Table I. Production of LT by Tonsillar B and T Cells

\begin{tabular}{|c|c|c|c|c|c|c|c|c|}
\hline \multirow[b]{3}{*}{ Experiment } & \multicolumn{6}{|c|}{ B cells } & \multirow{2}{*}{\multicolumn{2}{|c|}{$\begin{array}{c}\text { T cells } \\
\text { PMA }+\alpha \text { CD3 }\end{array}$}} \\
\hline & \multicolumn{2}{|c|}{$\mathrm{PMA}+\alpha \mu$} & \multicolumn{2}{|c|}{ PMA + SAC } & \multicolumn{2}{|c|}{$\begin{array}{l}\text { PMA }+\alpha \mu+ \\
\quad \text { SAC }\end{array}$} & & \\
\hline & - & $+\alpha \mathbf{L T}$ & - & $+\alpha \mathrm{LT}$ & - & $+\alpha \mathrm{LT}$ & - & $+\alpha \mathrm{L}$ \\
\hline & \multicolumn{8}{|c|}{$U / 10^{6}$ cells } \\
\hline 1 & 54 & $<10$ & 35 & $<10$ & 77 & $<10$ & ND & ND \\
\hline 2 & 82 & 20 & 245 & 27 & 340 & 20 & 720 & 26 \\
\hline 3 & 34 & $<10$ & 97 & $<10$ & 80 & $<10$ & 300 & 20 \\
\hline
\end{tabular}

Cytotoxicity assays using L929 cells were as described in Methods. Supernatants for assays were from three day cultures of cells stimulated with the indicated stimulants.

T cells have been considered to be the major cell type responsible for LT and TNF production. On a per cell basis, tonsillar $\mathrm{T}$ cells expressed two to three times as much $\mathrm{LT}$ and twice as much TNF mRNA as tonsillar B cells. Quantitations of LT and TNF cytokines by cytotoxicity assay and radioimmunoassay, respectively, showed that stimulated tonsillar $\mathrm{T}$ cell supernatants contained 3-4 times more LT (Table I) and 5-10 times more TNF (14) than the supernatants of stimulated tonsillar B cells. Though the responses of the two cell types were not directly comparable because of the requirement of different stimuli, the results suggest that $T$ cells can theoretically synthesize more of both LT and TNF than B cells. However, under immune response conditions that selectively stimulate B cells, or in tissue areas locally enriched in stimulated B cells, LT and TNF production may be contributed significantly by $B$ cells.

Current models of B and T cell $(22,23)$ activation hypothesize that two signals, one activating protein kinase $\mathrm{C}$ and the other elevating cytosolic free $\left[\mathrm{Ca}^{2+}\right]$, are required for lymphocyte activation. The expression of cytokine mRNA and protein by lymphocytes also requires these signals. The stimulation of tonsillar B cells to express LT is consistent with this model. Though LT expression is not effectively stimulated by PMA, SAC, or anti- $\mu$, the combinations of PMA plus SAC or PMA plus anti- $\mu$ stimulated B cells to express high levels of $L T$ mRNA. Similar modes of activation were observed with TNF (16), IL-2 (23), and IFN- $\gamma$ (24) gene expression in T cells, in

Table II. Production of LT by B Cell Lines

\begin{tabular}{|c|c|c|c|c|c|c|}
\hline \multirow[b]{3}{*}{ Cell line } & \multicolumn{6}{|c|}{ Stimulation } \\
\hline & \multicolumn{2}{|c|}{ None } & \multicolumn{2}{|c|}{ PMA } & \multicolumn{2}{|c|}{ PMA + A23187 } \\
\hline & - & $+\alpha \mathrm{LT}$ & - & $+\alpha \mathrm{LT}$ & - & $+\alpha \mathrm{LT}$ \\
\hline & \multicolumn{6}{|c|}{$U / 10^{6}$ cells } \\
\hline RPMI 1788 & 200 & ND & 980 & 230 & 1,140 & 196 \\
\hline WIH8 & 70 & ND & 400 & 24 & 400 & ND \\
\hline KAW15 & 250 & ND & 640 & 26 & 560 & 26 \\
\hline
\end{tabular}

Cells were stimulated with the indicated drugs for $24 \mathrm{~h}$. LT assays were performed as described in Methods. The results show one of two similar experiments. 
which anti-CD3 and PHA played a role equivalent to SAC and anti- $\mu$ in B cells. The activation requirements for B cell lines, however, were different from that of the primary tonsillar lymphocytes (Fig. 5). PMA alone was enough to induce high levels of LT mRNA expression, and the additional activation by the second signal A23187 only slightly increased peak LT mRNA expression (Fig. 5). This difference also occurred with the expression of TNF mRNA by the same B cell line (Fig. 5), and with the expression of both LT and TNF genes in T cell lines (16). The addition of A23187 did, however, reduce the lag time for peak LT and TNF mRNA accumulation in B cell lines, and prolonged the half-life of intracellular message for both cytokines. Whether this kinetic change is due to increased transcription rates of the two genes, or the reduced degradation rates of the mRNA's requires further studies.

The cytotoxic activities of the supernatants of activated tonsillar B cells were predominantly due to LT (Table I). However, Northern blot studies showed that using TNF and LT mRNA expression by tonsillar $T$ cells as the reference, these $B$ cells accumulate more TNF mRNA than LT mRNA (Fig. 6). This paradoxical observation can be explained by the hypothesis that TNF is selectively utilized by the stimulated B cells. This hypothesis is based on the findings that $(a)$ the same receptors that bind both LT and TNF have a tenfold lower binding affinity for LT (25), (b) LT has a 10-fold higher threshold concentration than TNF in stimulating endothelial cell secretion of IL-1 and hematopoietic growth factors $(25,26)$; and (c) TNF is rapidly utilized by stimulated tonsillar B cells (14). Since both LT and TNF were required for B cell proliferation (5-7), experiments designed to prove this hypothesis by blocking LT and TNF reutilization would be difficult to interpret.

Results on CsA inhibition studies (Fig. $7 \mathrm{~B}$ ) showed that LT mRNA accumulation in PMA plus anti-CD3-stimulated tonsillar $\mathrm{T}$ cells was exquisitely sensitive to CsA inhibition. LT mRNA accumulation was almost completely inhibited by 100 $\mathrm{ng} / \mathrm{ml} \mathrm{CsA}$ (Fig. $7 \mathrm{~B}$, lane 6 ). This is similar to the proliferation of peripheral blood T cells stimulated by PMA plus anti-CD3, which was almost completely inhibited by $100 \mathrm{ng} / \mathrm{ml} \mathrm{CsA} \mathrm{(27).}$ CsA has been shown to inhibit tonsillar B cell proliferation (18). However, the present study showed that the stimulated increase in LT mRNA accumulation in tonsillar B cells was relatively insensitive to CsA inhibition when compared with that in $\mathrm{T}$ cells. A similar resistance to CsA inhibition has also been demonstrated in the stimulated increases of several inducible monocyte mRNAs (28). Whether this resistance is due to differences in cell types or in the signals elicited by the different stimuli needs to be further examined.

\section{Acknowledgments}

We thank Drs. D. Caput, B. Beutler, and M. Kirschner for providing us with cDNA probes and Ms. K. Medina, Mr. C. Wasson, G. Yates, and C. Cantin for excellent technical assistance.

This work was supported in part by National Institutes of Health grants CA-34546, AI-25704, CA-37954, a grant from the Eleanor Naylor Dana Trust Fund, U. S. Public Health Service grant 5SO7RR05354, a grant from the Dermatologic Research Foundation of California Inc., and a grant from the Dermatology Foundation, Evanston, IL.

\section{References}

1. Granger, G. A., and T. W. Williams. 1968. Lymphocyte cytotoxicity in vitro: activation and release of a cytotoxic factor. Nature (Lond.). 218:1253-1254.

2. Ruddle, N. H., and B. H. Waksman. 1967. Cytotoxic effect of lymphocyte-antigen interaction in delayed hypersensitivity. Science (Wash. DC). 157:1060-1062.

3. Paul, N. L., and N. H. Ruddle. 1988. Lymphotoxin. Annu. Rev. Immunol. 6:407-438.

4. Granger, G. A., S. L. Orr, and R. S. Yamamofo. 1985. Lymphotoxins, macrophage cytotoxins, and tumor necrosis factors: an interrelated family of antitumor effector molecules. J. Clin. Immunol. 5:217-219.

5. Kehrl, J. H., M. Alvarez-Mon, G. A. Delsing, and A. S. Fauci. 1987. Lymphotoxin is an important $T$ cell-derived growth factor for human B cell. Science (Wash. DC). 238:1144-1146.

6. Kehrl, J. H., A. Miller, and A. S. Fauci. 1987. Effect of tumor necrosis factor $\alpha$ on mitogen-activated human B cells. J. Exp. Med. 166:786-791.

7. Shalaby, M. R., T. Espevik, G. C. Rice, A. J. Ammann, I. S. Figari, G. E. Ranges, and M. A. Palladino, Jr. 1988. The involvement of human tumor necrosis factors- $\alpha$ and $-\beta$ in the mixed lymphocyte reaction. J. Immunol. 141:499-503.

8. Beutler, B., and A. Cerami. 1988. The common mediator of shock, cachexia and tumor necrosis. Adv. Immunol. 42:213-231.

9. Ferrante, A., M. Nandoskar, E. J. Bates, D. H. B. Goh, and L. J. Beard. 1988. Tumour necrosis factor beta (lymphotoxin) inhibits locomotion and stimulates the respiratory burst and degranulation of neutrophils. Immunology. 63:507-512.

10. Garrett, I. R., B. G. M. Durie, G. E. Nedwin, A. Gillespie, T. Bringman, M. Sabatini, D. R. Bertolini, and G. R. Mundy. 1987. Production of lymphotoxin, a bone-resorbing cytokine, by cultured human myeloma cells. N. Engl. J. Med. 317:526-532.

11. Averbrook, B. J., R. S. Yamamoto, T. R. Ulich, E. W. B. Jeffes, I. Masunaka, and G. A. Granger. 1987. Purified native and recombinant human alpha lymphotoxin [Tumor necrosis factor (TNF)-beta] induces inflammatory reactions in normal skin. J. Clin. Immunol. 7:333-340.

12. Wong, G. H. W., and D. V. Goeddel. 1986. Tumour necrosis factors $\alpha$ and $\beta$ inhibit virus replication and synergize with interferons. Nature (Lond.). 323:819-822.

13. Bersani, L., F. Colotta, G. Peri, and A. Mantovani. 1987. Cytotoxic effector function of B lymphoblasts. J. Immunol. 139:645-648.

14. Sung, S.-S. J., L. K. L. Jung, J. A. Walters, W. Chen, C. Y. Wang, and S. M. Fu. 1988. Production of tumor necrosis factor/cachectin by human B cell lines and tonsillar B cells. J. Exp. Med. 168:1539-1551.

15. Jeffes, E. W. B., R. S. Yamamoto, A. R. Ahmed, and G. A. Granger. 1984. Lymphotoxin detected in the blister fluid of bullous pemphigoid patients. J. Clin. Immunol. 4:31-35.

16. Sung, S.-S. J., J. M. Bjorndahl, C. Y. Wang, H. T. Kao, and S. M. Fu. Production of tumor necrosis factor/cachectin by human T cell lines and peripheral blood $\mathrm{T}$ lymphocytes stimulated by phorbol myristate acetate and anti-CD3 antibody. J. Exp. Med. 167:937-953.

17. Nedospasov, S. A., A. N. Shakhov, R. L. Turetskaya, V. A. Mett, M. M. Azizov, G. P. Georgiev, V. G. Korobko, V. N. Dobrynin, S. A. Filippov, N. S. Bystrov, L. N. Shingarova, and Y. A. Ovchnnikov. 1986. Tandem arrangement of genes coding for tumor necrosis factor (TNF- $\alpha$ ) and lymphotoxin (TNF- $\beta$ ) in the human genome. Cold Spring Harbor Symp. Quant. Biol. 51:611-624.

18. Shevach, E. M. 1985. The effects of cyclosporin on the immune system. Annu. Rev. Immunol. 3:397-423.

19. Matsushima, K., A. Procopio, H. Abe, G. Scala, J. R. Ortaldo, and J. J. Oppenheim. 1985. Production of interleukin 1 activity by normal human peripheral blood B lymphocytes. J. Immunol. 135:1132-1136. 
20. Kawano, M., T. Hirano, T. Matsuda, T. Taga, Y. Horii, K. Iwato, H. Asaoku, B. Tang, O. Tanabe, H. Tanaka, A. Kiramoto, and T. Kishimoto. 1988. Autocrine generation and requirement of BSF-2/ IL-6 for human multiple myelomas. Nature (Lond.). 332:83-85.

21. Lotz, M., C. D. Tsoukas, S. Fong, C. A. Dinarello, D. A. Carson, and J. H. Vaughan. 1986. Release of lymphokines after Epstein Barr virus infection in vitro. I. Sources of and kinetics of production of interferons and interleukins in normal humans. J. Immunol. 136:3636-3642.

22. Cambier, J. C., and J. T. Ransom. 1987. Molecular mechanisms of transmembrane signaling in B lymphocytes. Annu. Rev. Immunol. 5:175-199.

23. Weiss, A., J. Imboden, K. Hardy, B. Manger, C. Terhorst, and J. Stobo. 1986. The role of the T3/antigen receptor complex in T-cell activation. Annu. Rev. Immunol. 4:593-619.

24. Hardy, K. J., B. Manger, M. Newton, and J. D. Stobo. Molecular events involved in regulating human interferon- $\gamma$ gene expression during T cell activation. J. Immunol. 138:2353-2358.
25. Locksley, R. M., F. P. Heinzel, H. M. Shepard, J. Agosti, T. E. Eessalu, B. B. Aggarwal, and J. M. Harlan. 1987. Tumor necrosis factors $\alpha$ and $\beta$ differ in their capacities to generate interleukin 1 release from human endothelial cells. J. Immunol. 139:1891-1895.

26. Broudy, V. C., J. M. Harlan, and J. W. Adamson. 1987. Disparate effects of tumor necrosis factor- $\alpha /$ cachectin and tumor necrosis factor- $\beta$ /lymphotoxin on hematopoietic growth factor production and neutrophil adhesion molecule expression by cultured human endothelial cells. J. Immunol. 138:4298-4302.

27. June, C. H., J. A. Ledbetter, M. M. Gillespie, T. Lindsten, and C. B. Thompson. 1987. T cell proliferation involving the CD28 pathway is associated with cyclosporine-resistant interleukin 2 gene expression. Mol. Cell. Biol. 7:4472-4481.

28. Granelli-Piperno, A., M. Keane, and R. M. Steinman. 1988. Evidence that cyclosporine inhibits cell-mediated immunity primarily at the level of the $T$ lymphocyte rather than the accessory cell. Transplantation. 46:53S-60S. 